\title{
Taboo, emotionally valenced, and emotionally neutral word norms
}

\author{
KRISTIN JANSCHEWITZ \\ University of California, Los Angeles, California
}

\begin{abstract}
Although taboo words are used to study emotional memory and attention, no easily accessible normative data are available that compare taboo, emotionally valenced, and emotionally neutral words on the same scales. Frequency, inappropriateness, valence, arousal, and imageability ratings for taboo, emotionally valenced, and emotionally neutral words were made by 78 native-English-speaking college students from a large metropolitan university. The valenced set comprised both positive and negative words, and the emotionally neutral set comprised category-related and category-unrelated words. To account for influences of demand characteristics and personality factors on the ratings, frequency and inappropriateness measures were decomposed into raters' personal reactions to the words versus raters' perceptions of societal reactions to the words (personal use vs. familiarity and offensiveness vs. tabooness, respectively). Although all word sets were rated higher in familiarity and tabooness than in personal use and offensiveness, these differences were most pronounced for the taboo set. In terms of valence, the taboo set was most similar to the negative set, although it yielded higher arousal ratings than did either valenced set. Imageability for the taboo set was comparable to that of both valenced sets. The ratings of each word are presented for all participants as well as for single-sex groups. The inadequacies of the application of normative data to research that uses emotional words and the conceptualization of taboo words as a coherent category are discussed. Materials associated with this article may be accessed at the Psychonomic Society's Archive of Norms, Stimuli, and Data, www.psychonomic.org/archive.
\end{abstract}

Although emotional word norms are easily accessible to investigators (see, e.g., Bellezza, Greenwald, \& Banaji, 1986; Bradley \& Lang, 1999), no normative data are readily available for a specific kind of emotional word: taboo words. The category of taboo words, broadly defined, includes profanities, vulgarities, sexual terms, racial epithets, and other insults (see Jay, 1992, 2000, for comprehensive treatments of taboo semantics). Cognitive psychologists and other investigators have used taboo words to demonstrate the effects of emotion in a number of domains of information processing; they are associated with enhanced attention (Anderson, 2005), superior recall (Jay, CaldwellHarris, \& King, 2008), and heightened autonomic response (Harris, Ayçiçegi, \& Gleason, 2003; LaBar \& Phelps, 1998) relative to emotionally neutral words.

Taboo words are also processed differently than are other kinds of emotional words. Word emotionality tends to be defined along dimensions of valence (evaluation: negative to positive) and arousal (the quality of being exciting or attention grabbing, often measured physiologically). The defining feature of taboo word emotionality is high arousal. Indeed, comparisons between low-arousal nontaboo words and taboo words have yielded differences in patterns of neural activity associated with initial word processing that correspond to differences in attention. That is, taboo words are processed more automatically (Kensinger
\& Corkin, 2004). A related finding is enhanced memory for taboo words relative to low-arousal valenced words (Jay et al., 2008; Kensinger \& Corkin, 2003, 2004). Taboo words have also been shown to enhance repetition priming relative to low-arousal words (Thomas \& LaBar, 2005).

The purpose of the present study was to provide normative data for taboo words, and as such it is novel in several ways. To begin with, taboo words are noticeably absent from standard measures of written frequency (e.g., Kučera \& Francis, 1967). Jay (1992) provided missing frequency data through a record of taboo words as spoken utterances (1986 field study) and provided both frequency and tabooness data for taboo words that are based on subjective ratings (1977 and 1978 rating studies). In the 1977 study, a small, complementary set of nontaboo words was rated for frequency and tabooness. With this exception, however, no study exists in which taboo and neutral words have been compared along the same kinds of frequency measures, which makes relative judgments of frequency across word type difficult. Whereas neutral and valenced nontaboo words can be quantified in terms of their emotional qualities and written frequency, taboo words are often compared alongside these words using incomparable frequency estimates (e.g., from the Internet; Kensinger \& Corkin, 2003). For this reason, participants in the present study were asked to rate sets of taboo,

K. Janschewitz, kjansche@ucla.edu 
emotionally valenced, and neutral words using the same method and scales.

A novel feature of the rating procedure that was used in this study concerns the measures of frequency and inappropriateness. These measures take advantage of the subjectivity inherent in rating studies by allowing raters to distinguish between their own judgments of a word and their estimations of the judgments of others regarding the word. For example, a word's inappropriateness was measured both from the point of view of the rater (offensiveness) and in terms of how the rater perceived the inappropriateness of the word to society at large (tabooness). The necessity for this kind of within-dimension distinction comes from Jay's (1992) finding about the inappropriateness of taboo words: The semantic or emotional property of the word per se may be different from the personal reaction of the rater to the word. Jay found that it is important to make it clear to a rater whether or not the rating is personally relevant; otherwise, the rating will be a composite of personality factors and semantics in unknown proportions. In most experiments, the question of whether the emotion elicited by an experimental stimulus comes from a personal reaction or from the more universal tabooness of the word has been unexplored. The present set of ratings should inform researchers who are interested in disentangling the contributions of these factors. In this context, offensiveness ratings were expected to be lower than tabooness ratings, based on some raters' tendencies to "act as if they are not offended by anything" (Jay, 1992, p. 161). Likewise, frequency was measured in terms of both how often the rater used words him- or herself (personal use) and how often the rater estimated the word to be used in general (familiarity). This distinction was made to complement the dual measures of inappropriateness, since there is a strong inverse relationship between word frequency and inappropriateness (Jay, 1992). It was expected that, for taboo words, personal use ratings would be lower than familiarity ratings, based on the demand characteristics of the experimental setting and on raters' desire to appear as if their speech patterns were more socially appropriate than average.

Other novel contributions of this set of norms are arousal and imageability ratings; no set of published norms has compared taboo, emotionally valenced, and neutral words on arousal or imageability measures. It was expected that, consistent with much previous research (e.g., Harris et al., 2003; Jay et al., 2008; Kensinger \& Corkin, 2004), taboo words would be rated as more arousing than either emotionally valenced or emotionally neutral words. Currently, no imageability data are available for taboo words, although some exist for valenced nontaboo words (see, e.g., Altarriba \& Bauer, 2004). These data suggest that valenced words are comparable to abstract neutral words; that is, emotional words are not highly imageable. Imageability ratings can be used to determine whether this nonemotional psycholinguistic factor contributes to taboo word effects that are otherwise assumed to be attributable to emotionality. For example, high imageability has been associated with enhanced memory (Dewhurst \& Conway, 1994; O'Neill, 2005). Although Altarriba and Bauer's finding of relatively low imageability ratings for valenced nontaboo concept words suggests that this might not be the case, taboo word imageability ratings are necessary to establish this point with confidence.

The emotionally valenced nontaboo words that were used in this study comprise sets of positive and negative words that have been normed previously by Bradley and Lang (1999). It was anticipated that the inclusion of emotional nontaboo words and the valence rating would be useful for investigators who are interested in manipulating arousal (as well as valence). In this case, the nontaboo emotional words can be construed as a medium-arousal category, and taboo words can be considered high arousal by comparison. Further, both the positive and negative sets that were rated here were constructed in such a way that there were high- and low-arousal sets within each. This within-set control for arousal level may not have entirely disentangled the contributions of valence and arousal to word emotionality, but it was an effort to make these qualities as independent as possible.

Taboo word valence was systematically assessed for the first time in this study. Small samples of taboo words have been shown to be negatively valenced, although valence norms for taboo words are not widely available. This is an interesting research question, both because valence ratings will be practically useful and because some investigators (e.g., Baumeister, Bratslavsky, Finkenauer, \& Vohs, 2001; Rozin \& Royzman, 2001) have noted a positive-negative asymmetry within language: more variability within categories of negative emotion words; more words for negative emotions and states; more strongly negative words than strongly positive words, and so forth. This study was a first attempt to examine the structure of the taboo lexicon with respect to both valence and arousal. Thus, it should be possible to determine whether the distribution of ratings skews consistently with the negativity bias.

Finally, within the set of neutral words that were used in this study, both category-related and category-unrelated words were defined. This distinction was intended to address a question that arises in memory and attention research that uses taboo words: Should taboo words be considered a distinct, cohesive category of words? In studies that have related emotional words to control sets of neutral words, category-related neutral words were often chosen because of the possibility that emotional effects are due to organizational processes that are a function of category coherence (e.g., negative-valence emotional words comprise a category of "bad things") rather than, or in addition to, arousal or valence. When category-unrelated neutral words are compared with emotional words, effects for the emotional word set that are attributable to semantic relatedness do occur. For example, in a recognition memory test, an increase in false-positive responses to emotional words due to "semantic cohesion" of the emotional word set has been demonstrated (Maratos, Allan, \& Rugg, 2000). When category-related neutral words have been compared with emotional words, some evidence has supported a strong version of the semantic relatedness claim (e.g., Talmi \& Moscovitch, 2004), but the bulk of the data have suggested that semantic relatedness is at best a partial explanation, unable to fully account for emotional ef- 
fects (see, e.g., Anderson, 2005; Doerksen \& Shimamura, 2001; Kensinger \& Corkin, 2003). Both category-related and category-unrelated neutral words were included in the ratings in order to accommodate investigators who endorse either of the claims and wish to choose stimuli accordingly.

\section{METHOD}

\section{Participants}

Participants were 84 undergraduate students ( 34 men and 50 women) from the University of California at Los Angeles. All were native English speakers. Participation was compensated with course credit. Data from 6 participants ( 1 man and 5 women) were excluded due to a failure to properly follow instructions.

\section{Materials}

Four hundred sixty words were included in the word ratings: 92 taboo words, 184 emotionally valenced words, and 184 emotionally neutral words. Taboo words were defined as words that were socially inappropriate, stemming from several semantic domains, including religion (goddamn or hell); sexuality, including both slang ( $p u s s y$ ) and clinical terms (vagina); scatology (shit); racial slurs (kike); and other insults (homo, whore, or bastard). The words were selected from those that appeared in Jay (1992) as well as at the discretion of the experimenter.

Emotionally valenced words were selected from Bradley and Lang's (1999) Affective Norms for English Words (ANEW). The ANEW database includes ratings for several hundred words on measures of valence and arousal; both measures range from 1 to 9 . For valence, larger numbers indicate positive valence, and smaller numbers indicate negative valence; a rating of about 5 is neither positive nor negative. For arousal, larger numbers indicate high arousal and smaller numbers indicate low arousal; the average arousal rating is approximately 5 . In the present study, the valenced set comprised 92 positive and 92 negative words. Each valence was subdivided into high-arousal and low-arousal sets. The positive set was defined by an average valence of 7.40 (in both high- and low-arousal conditions); the high-arousal positive set had an average ANEW arousal rating of 6.22 , whereas the low-arousal positive set had an average arousal rating of 4.56 . Similarly, the negative set was defined by an average valence of approximately 2.8 (2.81 for the high-arousal set, and 2.80 for the low-arousal set); the high-arousal negative set had an average ANEW arousal rating of 6.55 , whereas the low-arousal negative set had an average arousal rating of 4.56. It is important to note that the average arousal values of the high-arousal sets did vary by valence. We suggest that this is a natural property of the emotional lexicon that is related to a negativity bias in information processing (see, e.g., Baumeister et al., 2001; Rozin \& Royzman, 2001).

The category of neutral words was subdivided: 92 neutral words were category related (i.e., having to do with household objects [table] and activities [scrub]), and 92 were category unrelated (butter or cannon). Neutral words were chosen from the ANEW database and at the discretion of the experimenter. Where possible, valence and arousal ratings were computed from the ANEW ratings to ensure that these sets were, in fact, emotionally neutral. According to the ANEW statistics, the category-related neutral set had an average valence rating of 5.21 and an average arousal rating of 3.88 . The category-unrelated neutral set had an average valence rating of 5.25 and an average arousal rating of 3.91.

Written frequency was controlled across word set for all word types (except taboo words) according to Kučera and Francis's (1967) norms. The average written frequency estimates for the positive, negative, category-related, and category-unrelated sets were 28.78 , $26.20,27.84$, and 28.59, respectively. Estimates of written frequency for taboo words were not provided in Kučera and Francis. Taboo words contained an average of 5.58 letters $(S D=1.94)$ and 1.75 syllables $(S D=0.83)$. Positive valence words contained an average of 5.71 letters $(S D=1.68)$ and 1.74 syllables $(S D=0.74)$. Negative valence words contained an average of 5.70 letters $(S D=1.51)$ and 1.75 syllables $(S D=0.72)$. The category-related neutral set averaged 5.71 letters $(S D=1.73)$ and 1.71 syllables $(S D=0.78)$ per word, and the category-unrelated neutral set averaged 5.66 letters $(S D=1.67)$ and 1.80 syllables $(S D=0.58)$ per word. All of these word statistics are presented by word type in the Psychonomic Society Archive of Norms, Stimuli, and Data, along with the ratings that were obtained in this study.

\section{Measures}

Because of the size of the word set to be rated, words were presented in two packets to allow participants to take a break halfway through the rating process. The order of the presentation of a particular word was counterbalanced in such a way that it appeared the same number of times in the first packet as in the second packet across all participants. Two randomizations of each packet were constructed to further control for order effects. Thus, four randomized complete word lists were constructed. In order to be consistent with the ANEW ratings, each word was rated on a scale of 1 to 9 , with 9 being the highest possible rating, for seven qualities: personal use, familiarity, offensiveness, tabooness, valence, arousal, and imageability. Personal use was defined as the extent to which a participant used the word him- or herself. Familiarity was defined as the extent to which a participant had heard, read, or otherwise encountered the word in any setting (e.g., in a conversation with friends or in a movie). Offensiveness was defined as the extent to which a participant found the use of the word personally offensive or upsetting. Tabooness was defined as the extent to which a participant viewed the use of a word as offensive or upsetting to people in general. For this rating, participants were encouraged to think of the word being used in multiple contexts and by multiple types of speakers. Valence was defined as the extent to which a participant found the word good or bad, with larger numbers representing positive evaluation, smaller numbers representing negative evaluation, and a value of 5 indicating neither positive nor negative evaluation. Arousal was defined as the extent to which a participant found the word exciting or attention grabbing. Imageability was defined as the extent to which a participant found it easy to form a mental image of the word. The instructions are presented in Appendix A.

A short demographic questionnaire was also created. This questionnaire assessed age, sex, and English experience, and it included one question about religiosity (How religious are you?), measured on a scale of 1 to 5 . Religiosity has been shown to be an important contributory factor to self-reported projected frequency of use for taboo words (Mabry, 1975).

\section{Procedure}

The materials and experimental protocol were approved for use with human subjects by the Institutional Review Board of the University of California at Los Angeles. Before the data-collection period, participants were informed of the purpose of the study and were told that they would encounter offensive words during the course of the study. Participants were offered the opportunity to opt out of participating without penalty, but none chose to do so. Following the informed-consent procedure, participants completed the demographic questionnaire. Data collection began after an experimenter had read and confirmed participants' understanding of the instructions for and the meaning of the rating scales. Participants completed the questionnaires individually; completion time was approximately $3 \mathrm{~h}$, including a 5 -min break.

\section{RESULTS}

Ratings of taboo, positive-valence, negative-valence, category-unrelated neutral, and category-related neutral words are presented in alphabetical order by word type in Appendix B. The top 10 taboo words are rank ordered on 
each rating scale and are presented in Appendix B. Singlesex ratings are available in the Psychonomic Society Archive of Norms, Stimuli, and Data.

\section{Validity of the Measures}

Correlations between these data and other word norms were computed using Pearson's $r$. Both frequency measures were significantly positively correlated with Kučera and Francis's (1967) written frequency norms (377 shared words; personal use, $r=.43, p<.001$; familiarity, $r=$ $.41, p<.001)$. Although these were significant relationships, they were smaller than expected. Differences in the type of measure (subjective ratings vs. written frequency) and in the relative ages of the norms likely contributed to the magnitude of the effect.

Correlations were also computed between the present valence and arousal ratings and those in the ANEW database. The valence ratings obtained in the present study were significantly positively correlated with those in ANEW (316 shared words; $r=.94, p<.001$ ). The arousal ratings obtained in the present study were also significantly positively correlated with ANEW arousal ratings $(r=.72$, $p<.001)$. The correlations between the single-sex analyses of the present set of ratings and those in ANEW were as follows: valence for men, $r=.89, p<.001$; valence for women, $r=.94, p<.001$; arousal for men, $r=.67, p<$ .001 ; arousal for women, $r=.68, p<.001$.

For taboo words, both frequency measures were significantly positively correlated with Jay's 1986 estimate of spoken frequency (38 shared words; personal use, $r=$ $.50, p=.001$; familiarity, $r=.52, p=.001$; Jay, 1992). These frequency measures were also correlated with two other sets of spoken frequency estimates of taboo words that were reported in Jay and Janschewitz (2008b). Familiarity ratings were significantly positively correlated with a 1997 estimate (31 shared words; $r=.41, p=.02$; the personal use correlation trends in the same direction but is nonsignificant). Both sets of frequency measures were also significantly positively correlated with an estimate from 2006 (46 shared words; personal use, $r=.38, p=$ .01 ; familiarity, $r=.41, p=.005)$. The present set of ratings was most similar to sets of subjective frequency estimates from 1977 and 1978 that were reported in Jay (1992). Both frequency measures were significantly positively correlated with Jay's 1977 frequency ratings (24 shared words; personal use, $r=.81, p<.001$; familiarity, $r=.80, p<.001)$ and Jay's 1978 frequency ratings $(63$ shared words; personal use, $r=.71, p<.001$; familiarity, $r=.78, p<.001)$. Jay's rating studies also measured tabooness. Both inappropriateness measures were significantly positively correlated with Jay's 1977 tabooness ratings (offensiveness, $r=.56, p=.004$; tabooness, $r=.69$, $p<.001$ ) and Jay's 1978 tabooness ratings (offensiveness, $r=.60, p<.001$; tabooness, $r=.59, p<.001)$.

\section{Frequency Ratings}

Personal use and familiarity were significantly correlated for all word types (all $r \mathrm{~s}=.92$ or above; $p<.001$ ).

A 2 (frequency measure) $\times 5$ (word type) mixed ANOVA was conducted to determine whether frequency ratings varied systematically by word type. The main effects of frequency measure and word type were significant $\left[F(1,455)=1,795.39, M S_{\mathrm{e}}=0.07, p<.001, \eta_{\mathrm{p}}^{2}=\right.$ .80 , and $F(4,455)=9.64, M S_{\mathrm{e}}=2.43, p<.001, \eta_{\mathrm{p}}^{2}=.08$, respectively], as was the frequency measure $X$ word type interaction $\left[F(4,455)=45.14, M S_{\mathrm{e}}=0.07, p<.001\right.$, $\left.\eta_{\mathrm{p}}^{2}=.28\right]$. It should be noted that the taboo set was rated lower on the global measure of frequency than any other set $[$ all $t \mathrm{~s}(182) \geq 3.43, p \mathrm{~s} \leq .001$, uncorrected] except the category-unrelated set $[t(182)=1.36, \mathrm{n} . \mathrm{s}$. $]$. This result is somewhat difficult to interpret, and it may be qualified by the interaction. Post hoc $t$ tests were significant by frequency measure within each word type (all post hoc tests were evaluated using Bonferroni corrected alphas; note that uncorrected $p$ values are reported here). This reflects an overall tendency for raters to provide higher familiarity ratings than personal use ratings [all $t \mathrm{~s}(91) \geq 16.40$, $p<.001]$. The magnitude of the difference between the personal use and familiarity ratings, however, was numerically largest for taboo words (personal use, $M=3.64$, $S D=1.51$; familiarity, $M=4.79, S D=1.46)$, followed by negative words (personal use, $M=4.40, S D=1.07$; familiarity, $M=5.30, S D=0.94$ ), positive words (personal use, $M=4.77, S D=1.02$; familiarity, $M=5.44$, $S D=0.86$ ), category-unrelated neutral words (personal use, $M=4.17, S D=1.09$; familiarity, $M=4.78, S D=$ 0.99 ), and, finally, category-related neutral words (personal use, $M=4.66, S D=1.11$; familiarity, $M=5.13$, $S D=0.94)$. That is, raters thought they were more likely to encounter all types of words in various situations than to use the words themselves, a difference that was most pronounced for taboo words.

\section{Inappropriateness Ratings}

Offensiveness and tabooness ratings were significantly correlated for all word types (all $r \mathrm{~s} \geq .56, p \mathrm{~s}<.001$ ).

As with the frequency measures, a 2 (inappropriateness measure) $\times 5$ (word type) mixed ANOVA was conducted to determine whether inappropriateness ratings would vary systematically by word type. Both main effects of inappropriateness measure and word type were significant $\left[F(1,455)=531.62, M S_{\mathrm{e}}=0.11, p<.001, \eta_{\mathrm{p}}^{2}=.54\right.$, and $F(4,455)=343.35, M S_{\mathrm{e}}=0.75, p<.001, \eta_{\mathrm{p}}^{2}=.75$, respectively], as was the frequency measure $\times$ word type interaction $\left[F(4,455)=316.13, M S_{\mathrm{e}}=0.11, p<.001\right.$, $\left.\eta_{\mathrm{p}}^{2}=.74\right]$. That is, while the taboo set was rated as more inappropriate than any other set $[$ all $t \mathrm{~s}(182) \geq 16.12, p \mathrm{~s}<$ $.001]$, raters tended to provide tabooness ratings that were higher overall than offensiveness ratings. An analysis of the interaction clarifies these effects. Post hoc tests were significant by inappropriateness measure for all word types [all $t \mathrm{~s}(91) \leq 3.38, p \mathrm{~s} \leq .001]$ except categoryrelated words $[t(91)=2.19 ; p=.03$, uncorrected], for which the difference approached significance in the same direction. The magnitude of the difference between tabooness and offensiveness ratings, however, was much larger for taboo words (tabooness, $M=4.83, S D=1.45$; offensiveness, $M=2.77, S D=1.12$ ) than for the other word types: negative (tabooness, $M=1.71, S D=0.56$; offensiveness, $M=1.45, S D=0.40$ ), positive (tabooness, 
$M=1.21, S D=0.54$; offensiveness, $M=1.06, S D=$ 0.11 ), category-unrelated (tabooness, $M=1.10, S D=$ 0.14 ; offensiveness, $M=1.07, S D=0.11$ ), and categoryrelated (tabooness, $M=1.05, S D=0.14$; offensiveness, $M=1.02, S D=0.04)$. That is, the taboo set was rated significantly higher on both inappropriateness measures than were the other sets, though raters thought all types of words were more generally taboo than personally offensive. This difference was pronounced in the taboo set and nearly negligible for other word types (with the possible exception of negative words).

\section{Frequency-Inappropriateness Relationship}

Jay (1992) found a strong inverse relationship between frequency and inappropriateness measures for taboo words. Because the present set of ratings decomposed those measures based on a point-of-view distinction - that is, to whom the rating applies - correlations were computed to determine whether this distinction affected the frequencyinappropriateness relationship. Indeed, within the taboo set, it was found that the frequency measure of personal use yielded the predicted inverse relationship with both inappropriateness measures (offensiveness, $r=-.22, p=$ .04 ; tabooness, $r=-.25, p=.02$ ). Interestingly, the frequency measure of familiarity did not yield this relationship (both offensiveness and tabooness $r \mathrm{~s}=-.02$, n.s.).

\section{Valence}

A one-way ANOVA was performed on valence ratings to analyze the ratings by word type, and the result was significant $\left[F(4,455)=363.58, M S_{\mathrm{e}}=0.39, p<\right.$ $.001]$. Post hoc tests attested to the validity of the valence manipulation: Both neutral sets' valence ratings were approximately 5 , indicating neither negative nor positive evaluation (category-related, $M=5.11, S D=0.21$; category-unrelated, $M=5.05, S D=0.33$ ); they were also statistically equal $[t(182)=1.48$, n.s. $]$.

Comparisons between the positive-valence set and all other sets were significant [all $t \mathrm{~s}(182) \geq 15.20, p \mathrm{~s}<$ $.001]$, indicating that positive words were rated as significantly more positive $(M=6.29, S D=0.71)$ than all other word types. Likewise, the negative set $(M=3.30, S D=$ 0.52 ) was rated as significantly more negative than the positive or neutral sets [all $t \mathrm{~s}(182) \geq 27.33, p \mathrm{~s}<.001$ ] There was no difference in overall valence rating between the negative and taboo sets $[t(182)=2.05, p=.04$, uncorrected], although the taboo set trended in the direction of being rated slightly less negative than the negative set (taboo, $M=3.54, S D=1.01$ ). The taboo set was rated as significantly more negative than the positive and neutral sets $[$ all $t \mathrm{~s}(182) \geq 13.68, p \mathrm{~s}<.001]$.

\section{Arousal}

A one-way ANOVA was performed on arousal ratings to analyze the ratings by word type, and the result was significant $\left[F(4,455)=272.68, M S_{\mathrm{e}}=0.43, p<.001\right]$. Post hoc tests showed clear between-set differences in arousal. Both neutral sets yielded arousal ratings lower than those of any other set [category-related, $M=1.56, S D=0.29$; categoryunrelated, $M=1.66, S D=0.31$; all $t \mathrm{~s}(182) \geq 14.31$, all $p$ s $<.001]$. The neutral sets did not differ in arousal level $[t(182)=2.16, p=.03$, uncorrected $]$.

The positive and negative sets did not differ from each other in arousal ratings [positive, $M=2.92, S D=0.79$; negative, $M=2.89, S D=0.62 ; t(182)=0.31$, n.s.]. As expected, the high- and low-arousal groups that were created within each valenced set differed significantly in arousal ratings [positive high arousal, $M=3.17, S D=$ 0.80 ; positive low arousal, $M=2.66, S D=0.70$; positive arousal, $t(90)=3.26, p=.002 ;$ negative high arousal, $M=3.20, S D=0.53$; negative low arousal, $M=2.57$, $S D=0.55$; negative arousal, $t(90)=5.57, p<.001]$. The valenced sets yielded reliably higher arousal ratings than those of the neutral sets and reliably lower arousal ratings than those of the taboo set [both $t \mathrm{~s}(182) \geq 10.74$, $p \mathrm{~s}<.001]$. The taboo set $(M=4.34, S D=0.99)$ yielded significantly higher arousal ratings than those of all other word types [all $t \mathrm{~s}(182) \geq 10.74, p \mathrm{~s}<.001]$.

\section{Imageability}

A one-way ANOVA was performed on imageability ratings to analyze the ratings by word type, and the result was significant $\left[F(4,455)=40.02, M S_{\mathrm{e}}=3.37, p<.001\right]$. Post hoc tests indicated that the taboo, positive, and negative sets yielded comparable imageability ratings [taboo, $M=4.54, S D=1.69$; positive, $M=4.90, S D=2.15$; negative, $M=4.40, S D=1.78$; all $t \mathrm{~s}(182) \leq 1.71$, n.s.], and all were lower in imageability than either the categoryrelated or category-unrelated sets [all $t \mathrm{~s}(182) \geq 3.91, p \mathrm{~s}<$ .001 , uncorrected]. The category-related set yielded imageability ratings reliably higher than those of the unrelated set [category-related, $M=7.22, S D=1.13$; category-unrelated, $M=6.16, S D=2.22 ; t(182)=4.09, p<.001]$. This may be because the set of category-related words, which denoted household items and activities, included more concrete neutral words than did the category-unrelated set.

\section{Sex Differences}

For each measure, $t$ tests of raters' taboo means were conducted according to sex. Significant sex differences were found for personal use $[t(76)=2.71, p=.008]$, arousal $[t(76)=2.09, p=.04]$, and imageability $[t(76)=$ $3.22, p=.002]$. In all cases, men yielded ratings that were higher than those of women; that is, men reported that they used taboo words more often than women reported to (men, $M=4.04, S D=1.10$; women, $M=3.38, S D=$ $1.04)$, men reported that they found taboo words more attention grabbing than women reported to (men, $M=4.75$, $S D=1.67$; women, $M=4.03, S D=1.37)$, and men reported that they found taboo words more imageable than women reported to (men, $M=5.16, S D=1.47$; women, $M=4.15, S D=1.29$ ).

Since an analysis of individual words by sex was beyond the scope of this article, readers are encouraged to consult the Psychonomic Society Archive of Norms, Stimuli, and Data for single-sex ratings.

\section{Religiosity}

Raters' taboo means were correlated with their scores on the religiosity item (How religious are you?), which 
was rated on a scale of 1 to $5(M=2.79, S D=1.14)$. A significant positive correlation was obtained between religiosity and taboo word offensiveness $(r=.23, p=.04)$. A negative relationship between personal use of taboo words and religiosity approached significance $(p=.08)$. That is, raters who reported being more religious were more likely to report being offended by taboo words and marginally less likely to report using taboo words. It should be noted that religiosity was not significantly related to ratings on the associated frequency measure of familiarity, the associated inappropriateness measure of tabooness, or the arousal and imageability measures.

\section{DISCUSSION}

The experimental use of taboo words can benefit researchers in psychology, neuroscience, and linguistics, but only if the qualities of the words are clearly defined. The set of ratings that are presented in this article should be useful to researchers who are interested in these words as emotional entities.

The present set of ratings describes several ways in which taboo words are different from emotionally valenced and emotionally neutral words. The finding that both kinds of frequency estimates were lower for the taboo set than for most other sets contrasted with Jay's (1992) claim that taboo words are as frequent in language as neutral words are. It is important to note, however, that these estimates may not accurately describe the actual (objective) frequency of taboo words in written or spoken language. The present set's frequency measures correlated strongly with Jay's 1977 and 1978 rating studies (in Jay, 1992), but less so with his spoken estimates. Spoken frequency data collected by Mehl and colleagues set rates of swearing from $0.5 \%-0.7 \%$ of words spoken per day (Mehl, Gosling, \& Pennebaker, 2006; Mehl \& Pennebaker, 2003), or about 80 out of an average of 16,000 words (Mehl, Vazire, Ramírez-Esparza, Slatcher, \& Pennebaker, 2007). Mehl and colleagues used a definition of swearing that is narrower than the definition that was used here (e.g., sexual terms were considered separately); according to the present definition, swearing is even more frequent. Also, considerable variability in spoken estimates of taboo word use has been demonstrated at both the speaker level (e.g., some people curse frequently, others very rarely; Mehl et al., 2006) and the word level. Jay suggested that the distribution of frequency of use may be different for taboo words than for neutral words, inasmuch as the relatively small taboo set includes a few words that are used quite frequently and others that are hardly used at all. In thousands of instances of swearing recorded in his field studies, 10 words comprised $80 \%$ of the data (Jay \& Janschewitz, 2006).

Inconsistencies between records of written language, field studies of spoken language, and subjective estimates of language use raise the issue of which is the "best" or most accurate descriptive measure for a set of words. For frequency, subjective estimates may be relatively inaccurate in describing how often a person uses or encounters a particular word. Although subjectivity in this case is problematic, rating studies are often the easiest or the only way to describe other word properties (e.g., offensiveness or arousal), and the present set of ratings exploited the aspect of subjectivity by offering the rater the opportunity to make a point-of-view distinction within frequency and inappropriateness measures. The necessity for this distinction was validated in several ways. First, although some difference between the measures could be expected because raters were presented with two kinds of measures for the same quality, the differences between taboo word sets and other word sets were not of the same magnitude. Frequency measures for all word types showed that estimates of one's own use were lower than estimates of the likelihood of encountering the words from other sources, an effect that was especially large for taboo words. Likewise, although taboo words were rated higher than all other word types on both inappropriateness measures, the taboo set was rated as far more generally taboo than personally offensive, whereas the difference was quite a bit smaller for the other word types. Also, Jay's (1992) strong inverse relationship between frequency and inappropriateness ratings for taboo words obtained only for the personal use measure. That is, the inverse relationship between taboo word inappropriateness and the frequency with which the word was used was apparent only when raters made frequency judgments about their own use. Finally, religiosity ratings were related to the inappropriateness and (to a lesser extent) frequency measures only on the self-relevant dimensions of each.

The finding that the taboo set was more arousing but not of more extreme valence than the other word sets supports what has generally been assumed about taboo words: Their strong emotionality comes from arousal (see, e.g., Jay, 1992, 2000; Kensinger \& Corkin, 2003, 2004). Taboo words were shown to be as imageable as both sets of valenced nontaboo words; that is, they were less imageable than the neutral sets. This finding should be useful to investigators who wish to rule out high imageability as a possible explanation for emotion effects on information processing.

Regarding valence, these data show for the first time that the category of taboo words is most similar to that of negative words, supporting what has been suggested with smaller samples (e.g., Anderson, 2005). The semantic heterogeneity in the taboo category, however, should be a caveat to investigators: Individual differences and context are much more likely to influence the valence ratings of taboo words than to influence those of negative-valence words. That is, certain subcategories of taboo words (e.g., sexual terms) should not be considered uniformly negative in valence - a negative evaluation likely depends on the social or physical context (e.g., on experimental setting vs. a conversation with friends) and participant-level variables (e.g., religiosity, age, or sex; see Jay \& Janschewitz, 2008a, for a discussion of contextual variables that influence taboo word offensiveness evaluation). It should also be noted that the valence ratings that were obtained in this study may have been biased in the negative direction, 
both because participants encountered these words in the experimental setting and because the layout of the rating sheets resulted in most participants making valence judgments immediately after tabooness judgments.

A potential problem with these ratings concerns the extent to which participants rated the words on the basis of their denotative or connotative meaning. This may be a problem for the taboo set in particular, because emotional, connotative meaning is such a salient quality for taboo words - often more so than the literal meanings of the words (Jay, 1992, 2000). Arguably, the connotative meanings of many taboo words are based on their status as "bad," taboo, or socially unacceptable. Thus, evaluation based on connotative meaning may have contributed to the determination that the set as a whole was more negative than either the neutral or the positive sets. While this does not undermine the usefulness of the valence ratings - participants in studies in which taboo words were used were almost never given instructions about how to interpret the meaning of the words - it may be fruitful to disambiguate this issue in the future.

Similarly, an effort should be made to examine emotional and taboo words with multiple meanings. In the present study, when a particular word had more than one meaning, raters were not directed to base their ratings on a specific meaning. Explicitly providing this direction might have eliminated some confusion in the raters and made certain data cleaner (especially for mild taboo words, e.g., hump). It would also be interesting to focus specifically on words with multiple meanings in order to determine whether taboo meanings are consistently accessed primarily, secondarily, or in no particular order.

\section{A Note About the Sample}

Although the sample in the present study was typical for experimental research, it is unlikely to accurately represent the population at large on a number of dimensions (e.g., age, educational level, or social-economic status). These factors may have influenced the ratings, particularly with respect to the point-of-view distinctions within frequency and inappropriateness categories. A college sample likely comprises relatively young, diverse, liberal, and openminded students, who are used to being in situations in which casual swearing is tolerated. Accordingly, students may be less personally offended by taboo words, or they may report using or encountering taboo words more often than would a random sample of older adults. Because the demographic characteristics of the college sample were not extensively assessed and noncollege samples were not recruited, these data should not be assumed to generalize to the population at large.

To compound this problem, the method of norming involves averaging over individual differences, which eliminates variability that contributes to one's perception about the qualities of words. This is especially problematic for taboo words, because the meaning and emotional impact of taboo language depends on one's unique psychological, cultural, and neurological background (Jay, 2000). For example, taboo words elicit more autonomic reac- tivity in one's native language than in a second language (Harris et al., 2003), a finding that correlates with behavioral evidence that has shown that the emotional force of taboo words decreases with the order in which additional languages are learned (Dewaele, 2004). The correlations between religiosity and some of the measures in this study also attest to the influence of individual differences on taboo word evaluation.

Similarly, context plays a considerable role in how the emotionality of taboo language is perceived (Jay, 1992, 2000; Jay \& Janschewitz, 2008a), but these ratings were made independently of biasing context. Even with these limitations, however, this study has shown that taboo words do not behave like other word categories, particularly in the distinctions within frequency and inappropriateness measures, and on the arousal measure. Future studies should expand on the dimensions examined here in conjunction with psychological variables (e.g., sexual anxiety, age, cultural background) and contextual variables (e.g., speaker-listener relationship, location).

Finally, an examination of taboo word properties by gender should be conducted for a subset of taboo words that have been shown to be particularly offensive to males and females (as in Jay, 1992, 2000).

\section{Taboo Words As a Category}

Talmi and Moscovitch (2004) make the important point that semantic relatedness accounts at least partially for some effects of emotional words, particularly in the context of memory and attention research; accordingly, category-related neutral words are often used as neutral foils to control for effects of category cohesion among taboo words. Considering the substantial variability in the semantic domains that make up the taboo lexicon, it is important to stress that to be considered a category, taboo words should be related in meaning. That is, emotional meaning should be considered distinct from semantic meaning, and researchers who limit neutral foils to category-related words should also limit taboo words to a certain taboo subcategory (e.g., sexual terms). The experiments by Anderson (2005) were well-constructed in this respect; valence was used to define categories of emotional words.

The data that are presented here show that the "category" of taboo words is not statistically similar to negativevalence or positive-valence words or to category-related or category-unrelated neutral words, and could not easily be equated with those categories on a number of dimensions, except letter and syllable length (see Mabry, 1975). A more thorough and accurate understanding of taboo words would necessitate a subdivision of the present category along various dimensions (e.g., semantic category, valence, degree of arousal, and tabooness); until then, it will be difficult to be confident about the characteristics that are needed for words to match taboo words for stimulus selection. More generally, it would be linguistically and anthropologically interesting to consider subcategories of taboo words in terms of the dimensions that have been considered in this study. 


\section{AUTHOR NOTE}

The author gratefully acknowledges Theresa Khoo and Geraldine Mapel for their assistance with data collection, and Tim Jay, Barbara Knowlton, and Dan Greenberg for their helpful comments on earlier versions of the manuscript. Correspondence concerning this article should be addressed to K. Janschewitz, Department of Psychology, University of California at Los Angeles, Los Angeles, CA 90095-1563 (e-mail: kjansche@ucla.edu).

\section{REFERENCES}

Altarriba, J., \& Bauer, L. M. (2004). The distinctiveness of emotion concepts: A comparison between emotion, abstract, and concrete words. American Journal of Psychology, 117, 389-410.

Anderson, A. K. (2005). Affective influences on the attentional dynamics supporting awareness. Journal of Experimental Psychology: General, 134, 258-281.

Baumeister, R. F., Bratslavsky, E., Finkenauer, C., \& Vohs, K. D. (2001). Bad is stronger than good. Review of General Psychology, 5, 323-370.

Bellezza, F. S., Greenwald, A. G., \& Banaji, M. R. (1986). Words high and low in pleasantness as rated by male and female college students. Behavior Research Methods, Instruments, \& Computers, 18, 299-303.

Bradley, M. M., \& Lang, P. J. (1999). Affective norms for English words $(A N E W)$ : Instruction manual and affective ratings (Tech. Rep. C-1). Gainesville: University of Florida, Center for Research in Psychophysiology.

DewAELE, J.-M. (2004). The emotional force of swearwords and taboo words in the speech of multilinguals. Journal of Multilingual \& Multicultural Development, 25, 204-222.

Dewhurst, S. A., \& Conway, M. A. (1994). Pictures, images, and recollective experience. Journal of Experimental Psychology: Learning, Memory, \& Cognition, 20, 1088-1098.

Doerksen, S., \& Shimamura, A. P. (2001). Source memory enhancement for emotional words. Emotion, 1, 5-11.

Harris, C. L., Ayçiçegi, A., \& Gleason, J. B. (2003). Taboo words and reprimands elicit greater autonomic reactivity in a first language than in a second language. Applied Psycholinguistics, 24, 561-579.

JAY, T. (1992). Cursing in America: A psycholinguistic study of dirty language in the courts, the movies, in the schoolyards, and on the streets. Philadelphia: John Benjamins.

JAY, T. (2000). Why we curse: A neuro-psycho-social theory of speech. Philadelphia: John Benjamins.

JaY, T., Caldwell-Harris, C., \& King, K. (2008). Recalling taboo and nontaboo words. American Journal of Psychology, 121, 83-103.

JAY, T., \& JANSchewITZ, K. (2006, July). Swearing with friends and enemies in high and low places. Paper presented at the Linguistic Impoliteness and Rudeness: Confrontation and Conflict in Discourse Conference, Huddersfield, U.K.

JAY, T., \& JANSCHEWITZ, K. (2008a). The pragmatics of swearing. Journal of Politeness Research, 4, 267-288.

JAY, T., \& JANSCHEWITZ, K. (2008b). Taboo word frequency: Swearing in public. Manuscript submitted for publication.

Kensinger, E. A., \& Corkin, S. (2003). Memory enhancement for emotional words: Are emotional words more vividly remembered than neutral words? Memory \& Cognition, 31, 1169-1180.
Kensinger, E. A., \& Corkin, S. (2004). Two routes to emotional memory: Distinct neural processes for valence and arousal. Proceedings of the National Academy of Sciences, 101, 3310-3315.

KuČERA, H., \& Francis, W. N. (1967). A computational analysis of present-day American English. Providence, RI: Brown University Press.

LaBar, K. S., \& PhelPs, E. A. (1998). Arousal-mediated memory consolidation: Role of the medial temporal lobe in humans. Psychological Science, 9, 490-493.

MABRY, E. (1975). A multivariate investigation of profane language. Central States Speech Journal, 26, 39-44.

Maratos, E. J., Allan, K., \& RugG, M. D. (2000). Recognition memory for emotionally negative and neutral words: An ERP study. Neuropsychologia, 38, 1452-1465.

Mehl, M. R., Gosling, S. D., \& Pennebaker, J. W. (2006). Personality in its natural habitat: Manifestations and implicit folk theories of personality in daily life. Journal of Personality \& Social Psychology, 90, 862-877.

Mehl, M. R., \& Pennebaker, J. W. (2003). The sounds of social life: A psychometric analysis of students' daily social environments and natural conversations. Journal of Personality \& Social Psychology, 84, 857-870.

Mehl, M. R., Vazire, S., Ramírez-Esparza, N., Slatcher, R. B., \& Pennebaker, J. W. (2007). Are women really more talkative than men? Science, 317, 82.

O'NeILL, W. (2005). Word-imagery effects on recollection and familiarity in recognition memory. Perceptual \& Motor Skills, 100, 716-722.

Rozin, P., \& Royzman, E. B. (2001). Negativity bias, negativity dominance, and contagion. Personality \& Social Psychology Review, 5, 296-320.

Talmi, D., \& Moscovitch, M. (2004). Can semantic relatedness explain the enhancement of memory for emotional words? Memory \& Cognition, 32, 742-751.

Thomas, L. A., \& LaBAR, K. S. (2005). Emotional arousal enhances word repetition priming. Cognition \& Emotion, 19, 1027-1047.

\section{ARCHIVED MATERIALS}

The following materials associated with this article may be accessed through the Psychonomic Society's Archive of Norms, Stimuli, and Data, www.psychonomic.org/archive.

To access these files, search the archive for this article using the journal name (Behavior Research Methods), the first author's name (Janschewitz), and the publication year (2008).

FILE: Janschewitz-BRM-2008.zip

DESCRIPTION: The compressed archive file contains six files:

JanschewitzB386appB.txt, containing word ratings and associated statistics (all participants).

JanschewitzB386appB.xls, containing the above information in Excel spreadsheet format.

JanschewitzB386appC.txt, containing word ratings and associated statistics (men only).

JanschewitzB386appC.xls, containing the above information in Excel spreadsheet format.

JanschewitzB386appD.txt, containing word ratings and associated statistics (women only).

JanschewitzB386appD.xls, containing the above information in Excel spreadsheet format.

AUTHOR’s E-MAIL ADDRESS: kjansch@ucla.edu. 


\section{APPENDIX A}

\section{Instructions for Word Ratings}

In this study we are interested in how people perceive words. You will be given a list of words-your task is to rate each word according to the scales that are presented on this page. Please be as honest as possible in your judgments; they are very important to us! Work at a rapid pace and don't spend too much time on each word. Make your ratings based on your first reaction to the word. You will be given a break halfway through.

\section{Read the scales carefully before you start rating the words!}

Personal use: How often do YOU use the word in any way-speaking or writing? Give a 1-9 rating:

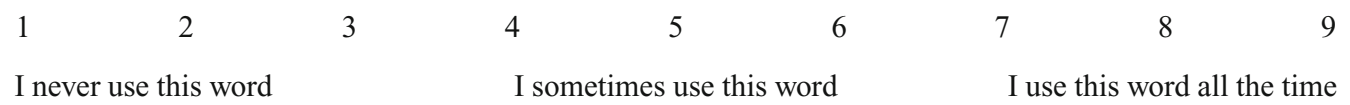

Familiarity: How often do you encounter the word? For example, you may hear it used in a conversation, on the radio, in a movie or on TV, or you may read the word in a magazine, book, on the Internet, etc. Give a 1-9 rating:

$\begin{array}{lllllllll}1 & 2 & 3 & 4 & 5 & 6 & 7 & 8 & 9\end{array}$

I never encounter this word

I sometimes encounter this word

I encounter this word all the time

Offensiveness: How offensive is this word to YOU? Give a 1-9 rating:

$\begin{array}{lllllllll}1 & 2 & 3 & 4 & 5 & 6 & 7 & 8 & 9\end{array}$

I am not at all offended by this word

This word is very offensive to me

Tabooness: How taboo or socially unacceptable is the word to people in general? Imagine the word being used at work, in a classroom, at a religious service, at a cocktail party, with friends, with family, etc. Give a 1-9 rating:

$\begin{array}{rrrrrrrrr}1 & 2 & 3 & 4 & 5 & 6 & 7 & 8 & 9 \\ \text { Not at all taboo } & & & \text { Medium taboo } & & & \text { Very taboo }\end{array}$

Valence: How positive or negative is the word? Give a 1-9 rating:

$\begin{array}{lllllllll}1 & 2 & 3 & 4 & 5 & 6 & 7 & 8 & 9\end{array}$

Strongly negative

Not negative or positive

Strongly positive

Arousal: How exciting is the word? Consider how much the word grabs your attention. Give a 1-9 rating:

$\begin{array}{llllllll}1 & 3 & 4 & 5 & 6 & 7 & 8 & 9 \\ \text { Not at all arousing } & & & \text { Medium arousing } & & & \text { Very arousing }\end{array}$

Imagery: How easily does the word bring an image to mind? When you think of the word, can you picture what it is? If this is easy, the word is high in imagery. For example, a word like "apple" has more imagery than a word like "honor." Give a 1-9 rating:
12
23
4
5
6
7
8
9

Doesn't bring an image to mind

Brings a vivid image to mind

\section{CHECK BACK TO THIS SHEET WHILE YOU ARE MAKING YOUR RATINGS \\ SO YOU REMEMBER WHAT THE SCALES MEAN!}

If you have questions, ask the experimenter!

Thank you! 
APPENDIX B

Top 10 Taboo Words for Each Measure

\begin{tabular}{|c|c|c|c|c|c|}
\hline \multicolumn{3}{|c|}{ Personal Use } & \multicolumn{3}{|c|}{ Familiarity } \\
\hline Word & $M$ & $S D$ & Word & $M$ & $S D$ \\
\hline stupid & 6.60 & 2.09 & shit & 7.42 & 1.75 \\
\hline damn & 6.52 & 2.27 & fuck & 7.14 & 2.11 \\
\hline dumb & 6.39 & 2.01 & stupid & 7.13 & 1.84 \\
\hline pee & 6.30 & 2.22 & damn & 7.05 & 1.84 \\
\hline lame & 6.29 & 2.27 & bitch & 7.00 & 1.77 \\
\hline shit & 6.23 & 2.47 & ass & 6.78 & 1.93 \\
\hline suck & 6.16 & 2.25 & dumb & 6.71 & 1.96 \\
\hline ass & 5.88 & 2.46 & suck & 6.59 & 2.22 \\
\hline butt & 5.82 & 2.35 & boobs & 6.53 & 1.94 \\
\hline fuck & 5.79 & 2.72 & gay & 6.53 & 2.14 \\
\hline \multicolumn{3}{|c|}{ Offensiveness } & \multicolumn{3}{|c|}{ Tabooness } \\
\hline Word & $M$ & $S D$ & Word & $M$ & $S D$ \\
\hline nigger & 6.64 & 2.82 & nigger & 8.45 & 1.20 \\
\hline cunt & 5.08 & 2.83 & buttfuck & 7.91 & 1.56 \\
\hline fag & 5.08 & 2.81 & motherfucker & 7.75 & 1.63 \\
\hline cocksucker & 5.00 & 2.82 & cocksucker & 7.73 & 1.68 \\
\hline chink & 4.97 & 2.78 & fuck & 7.50 & 1.80 \\
\hline motherfucker & 4.83 & 2.85 & cunt & 7.40 & 2.06 \\
\hline buttfuck & 4.82 & 2.81 & fag & 7.13 & 2.04 \\
\hline bitch & 4.60 & 2.54 & chink & 6.75 & 2.45 \\
\hline retard & 4.52 & 2.56 & blowjob & 6.61 & 2.08 \\
\hline whore & 4.45 & 2.62 & pussy & 6.60 & 2.01 \\
\hline \multicolumn{3}{|c|}{ Positive Valence } & \multicolumn{3}{|c|}{ Negative Valence } \\
\hline Word & $M$ & $S D$ & Word & $M$ & $S D$ \\
\hline orgasm & 6.63 & 1.80 & nigger & 1.42 & 0.85 \\
\hline climax & 6.04 & 1.26 & motherfucker & 1.80 & 0.92 \\
\hline breasts & 5.51 & 1.29 & fag & 1.87 & 1.24 \\
\hline boobs & 5.13 & 1.54 & cunt & 2.05 & 1.45 \\
\hline booty & 4.97 & 1.03 & whore & 2.13 & 1.11 \\
\hline randy & 4.83 & 0.94 & cocksucker & 2.16 & 1.16 \\
\hline nipples & 4.79 & 1.23 & bitch & 2.18 & 1.18 \\
\hline vagina & 4.79 & 0.96 & hell & 2.19 & 1.21 \\
\hline ejaculate & 4.65 & 1.45 & shithead & 2.32 & 1.12 \\
\hline semen & 4.64 & 0.96 & slut & 2.33 & 1.04 \\
\hline \multicolumn{3}{|c|}{ Arousal } & \multicolumn{3}{|c|}{ Imageability } \\
\hline Word & $M$ & $S D$ & Word & $M$ & $S D$ \\
\hline nigger & 7.03 & 2.62 & breasts & 7.83 & 1.62 \\
\hline cocksucker & 6.30 & 2.48 & nipples & 7.83 & 1.63 \\
\hline fuck & 6.26 & 2.38 & penis & 7.82 & 1.78 \\
\hline motherfucker & 6.22 & 2.55 & boobs & 7.78 & 1.56 \\
\hline pussy & 6.03 & 2.12 & butt & 7.44 & 1.91 \\
\hline buttfuck & 5.91 & 2.63 & vagina & 7.32 & 2.32 \\
\hline blowjob & 5.77 & 2.51 & balls & 7.01 & 2.40 \\
\hline cunt & 5.77 & 2.72 & tits & 7.00 & 2.29 \\
\hline orgasm & 5.75 & 2.43 & dildo & 6.84 & 2.33 \\
\hline clit & 5.48 & 2.57 & ass & 6.74 & 2.36 \\
\hline
\end{tabular}

(Manuscript received September 11, 2007; revision accepted for publication March 12, 2008.) 